OPEN ACCESS

Edited by:

Ali Derakhshan,

Golestan University, Iran

Reviewed by:

Majid Elahi Shirvan,

University of Bojnord, Iran

Tahereh Taherian,

Yazd University, Iran

${ }^{*}$ Correspondence:

Yijun Zeng

princehonor@126.com

Specialty section:

This article was submitted to

Educational Psychology,

a section of the journal

Frontiers in Psychology

Received: 07 July 2021

Accepted: 23 July 2021

Published: 12 August 2021

Citation:

Zeng Y (2021) A Review

of Foreign Language Enjoyment

and Engagement.

Front. Psychol. 12:737613.

doi: 10.3389/fpsyg.2021.737613

\section{A Review of Foreign Language Enjoyment and Engagement}

\author{
Yijun Zeng* \\ Department of International Business, Hainan College of Foreign Studies, Wenchang, China
}

The introduction of positive psychology into foreign/second language learning has led to a multitude of novel theoretical and empirical studies. Foreign language enjoyment (FLE) is regarded as a response to the widely examined concept of classroom anxiety. The majority of these studies have investigated the effect of learners' and teachers' characteristics (Xie and Derakhshan, 2021) pertaining to FLE on learners' academic achievement and their engagement in classroom tasks. Following a seminal study by Dewaele and Maclntyre (2014) and the development of the primary FLE scale, some researchers evaluated the extent of learners' enjoyment in the language learning environment; these studies approved the effectiveness and prominence of FLE throughout the learning process. The present review is an attempt to review studies on FLE during the past two decades. The related literature confirms the significance and efficiency of promoting FLE in the classroom because it brings about higher levels of motivation and engagement among language learners and leads to prolonged success and achievement. A summary of the major efforts regarding this area of research is presented in this study.

Keywords: positive psychology, motivation, engagement, foreign language enjoyment, second language acquisition, anxiety

\section{INTRODUCTION}

This manuscript is an attempt to investigate foreign language enjoyment (FLE), as a prominent feature of positive education (PE). The introduction of Positive Psychology (PP) can contribute to leading people toward success in their lives (Seligman and Csikszentmihalyi, 2000; Csikszentmihalyi and Nakamura, 2011). MacIntyre and Gregersen (2012) claimed that PP should be implemented in SLA because it is necessary to examine and affect students' emotions so that they can flourish and move toward their desirable objectives in future. Since 2016, there has been a shift toward PP in SLA (Lake, 2013). The proponents of this novel area of inquiry have intended to prepare the grounds for further research on the impact of PP in education and particularly language teaching and learning (Dewaele and MacIntyre, 2014; Gregersen and MacIntyre, 2017; Fathi and Derakhshan, 2019; Derakhshan et al., 2021; Pishghadam et al., 2021). This study attempts to appraise the present literature on FLE to observe the rationale and purposes of the studies and their empirical findings, determine those areas of research that have been disregarded, and propose some new topics for further research. 


\section{THEORETICAL BACKGROUND}

\section{FLE as a PP Construct}

Damasio (1994) and Fredrickson (2004) argued that learning is beyond affective factors and involves a multitude of factors such as communication, rapport, and identity. Having focused on emotion theory and earlier studies on affective factors in FL/SL learning, Seligman and Csikszentmihalyi (2000) introduced positive concepts into educational psychology. They asserted that it is necessary for language teaching/learning practitioners to consider well-being, hope, empathy, mindfulness, communicative skills, etc., to make a balance in the literature (Snyder and Lopez, 2009; Macintyre et al., 2019).

Seligman (2018) identified the building blocks of wellbeing in his PERMA model (Positive emotion, Engagement, Relationships, Meaning, and Achievement). Accordingly, FLE can be regarded as the realization of the Positive Emotion element in this model. Moreover, Fredrickson (2001) highlighted the "broadening-and-building" nature of positive emotions as the psychological capacity of individuals, which can lead to expansion of their perception. In language learning, FLE refers to learners' endeavors to meet learning challenges and broaden their knowledge and proficiency in the classroom (MacIntyre, 2016). Moreover, Botes et al. (2020) concluded that FLE occurs when learners can find appropriate responses to their psychological needs in the classroom. Pekrun et al. (2007) highlighted that enjoyment can result in persistent determination as well as positive and enthusiastic engagement in educational tasks (Mierzwa, 2018). Furthermore, language learners' evaluation of their own behavior may lead to the feeling of anxiety or foreign language enjoyment (Wei et al., 2019). Consequently, the implementation of PP in language learning might result in academic attainment and success.

\section{EMPIRICAL STUDIES}

Empirical studies on FLE can be categorized into the following four types of research:

\section{Validity of the FLE Measurements}

Since the study by Dewaele and MacIntyre (2014) is regarded as the building block of further research in FLE, it is imperative to start this section by highlighting the procedure of this research. They aimed to explore the correlation between enjoyment and anxiety in the language learning process. For this purpose, 1746 language learners with 90 different linguistic backgrounds and nationalities were selected. These learners were studying English, French, Spanish, Dutch, and German. The participants were selected to complete a researcher-made questionnaire on the web. The instrument contained 29 items (21 items developed to measure FLE observing positive emotions regarding the teacher, peers, and the learning experience, as well as eight items were extracted from the FLCA Scale) (see Appendix Figure A1). Once the questionnaire was completed, participants were asked to answer the following open-ended question: "Describe one specific event or episode in your FL class that you really enjoyed, and describe your feeling in as much detail as possible" (Dewaele and MacIntyre, 2014, p. 246). Dewaele and MacIntyre (2016) applied some modifications to the original FLE Scale and developed a 14-item questionnaire with an internal consistency coefficient of 0.86 . Given the acceptable reliability and validity of the proposed instrument, many scholars have employed this FLE scale or the translated versions in their studies (e.g., the Chinese version developed by Li et al., 2018).

Li et al. (2018), used a mixed-methods approach to evaluate the validity of the Chinese version of the FLE scale. Eventually, they proposed a 11-item scale within three factors of FLEPrivate, FLE-Teacher, and FLE-Atmosphere. In a similar vein, Jin and Zhang (2018) investigated the relationship between FLE and academic achievement among 320 Chinese students. They developed a 17-item scale [English Classroom Enjoyment Scale (ECES)] examining three factors including Enjoyment of Teacher Support, Enjoyment of Student Support, and Enjoyment of Foreign Language Learning, which was revised by the same authors in 2019. The revised version of ECES contained 16 items and was claimed to provide a more reliable instrument with more efficient psychometric properties.

Alongside the developments in the measurement of FLE in the above mentioned studies, Elahi Shirvan et al. (2021) employed a longitudinal confirmatory factor analysis to evaluate the psychometric properties of FLE scales over time. They also concluded that language learners with higher levels of L2 FLE did not experience great changes over time, while those with the initially lower level of FLE reported significant changes in this construct in the long run.

\section{The Association Between FLE and Demographic Variables}

Researchers have examined the relationship between different demographic variables and FLE. In terms of age, for instance, Dewaele et al. (2018) as well as Dewaele and MacIntyre (2014) asserted that younger language learners indicated lower levels of FLE. They also revealed that university students showed higher levels of FLE compared to high-school students. Besides, there has been inconsistencies among scholars over the impact of gender on FLE. Some studies provide that female language learners have demonstrated greater FLE (Dewaele and MacIntyre, 2016), whereas other researchers argued that there is an insignificant difference between the two gender in term of language enjoyment (Mierzwa, 2018; Alenezi, 2020). Since there has been a few researches on the impact of demographic characteristics on FLE, it is imperative to conduct further studies to provide reliable outcomes and implications.

\section{The Link Between FLE and Individual Difference Variables}

Foreign language enjoyment has been widely evaluated in association with foreign language anxiety (FLA). Dewaele and MacIntyre (2014) are considered the Pioneering authors in this regard as they have attempted to observe and compare negative (FLA) and positive (FLE) emotions. Other scholars have also examined the correlation between FLA and FLE; the 
summary of findings of such studies highlights a fairly negative relationship between these two concepts (Dewaele and Dewaele, 2017; Dewaele and Alfawzan, 2018; Resnik and Dewaele, 2020).

On the other hand, research on FLA has focused on different variables such as academic achievement, willingness to communicate (WTC), and etc. Since WTC refers to the learner's intention to speak up and communicate with the teacher and peers in the classroom, there might be a correlation between WTC and learners' FLE (Khajavy et al., 2018). Correspondingly, scholars have decided to conduct similar studies concerning FLE in the classroom (Dewaele, 2019; Elahi Shirvan and Taherian, 2020). Consequently, Dewaele (2019) argued that it is necessary for language teachers to create a positive atmosphere in the classroom, which can help develop and promote WTC. As a result of such positive environment, language learners could also expand their language learning enjoyment so as to succeed in achieving their linguistic-related objective.

\section{FLE as a Complex and Dynamic Construct}

Several studies demonstrated that FLE is a complicated and dynamic concept. Dewaele and Dewaele (2017) implemented a dynamic approach to investigate changes in FLE. All the participants in their study reported a growing FLE over time. They further asserted that learner's variables might not be able to predict language learning achievement, which indicated the dynamic nature of FLE. In addition, Elahi Shirvan and Talebzadeh (2018) argued that language enjoyment changes from topic to topic and among individuals, since learners have experienced various degrees of FLE throughout the learning process in the classroom. This finding can contribute to the effectiveness of interpersonal as well as inherent variables on language learners experiences.

Similarly, Li et al. (2018) conducted a study on the fluctuation of enjoyment and anxiety in the classroom. They further argued that poor linguistic capabilities and the lack of motivation can lead to various levels of FLE and FLCA among language learners. Moreover, Elahi Shirvan et al. (2020) aimed to investigate the extent of changes in FLE among language learners. For this

\section{REFERENCES}

Alenezi, S. M. (2020). Foreign language enjoyment and anxiety among the Northern Borders University EFL students: links to gender and majors. J. Educ. Psychol. Soc. Res. 39, 1203-1233. doi: 10.21608/jsrep.2020.86081

Botes, E., Dewaele, J.-M., and Greiff, S. (2020). The power to improve: effects of multilingualism and perceived proficiency on enjoyment and anxiety in foreign language learning. Eur. J. Appl. Linguistics 8, 1-28. doi: 10.1515/eujal-20200003

Csikszentmihalyi, M., and Nakamura, J. (2011). "Positive psychology: where did it come from, where is it going?," in Designing Positive Psychology: Taking Stock and Moving Forward, eds M. K. Sheldon, T. B. Kashdan, and M. F. Steger (New York: Oxford University Press), 3-8.

Damasio, A. R. (1994). Descartes' Error: Emotion, Reason, and the Human Brain. New York: Avon Books.

Derakhshan, A., Qafouri, M., and Faribi, M. (2021). An investigation into the demotivating and remotivating factors among Iranian MA purpose, they employed an ecological momentary evaluation approach using journals, interviews, and enjoyments. Findings of their research indicated that FLE changes from moment to moment and also from months to months.

Additionally, a seminal study was carried out by Dewaele and Dewaele (2020) so as to assess the effect of two different teachers on probable changes in FLE among language learners. They concluded that the teacher's use of target language in the classroom and learners' positive perception of the teacher can lead to a greater level of FLE.

\section{SUGGESTIONS FOR FUTURE RESEARCH}

Dewaele and MacIntyre (2016) concluded that foreign language enjoyment is primarily influenced by the teachers' behavior. Consequently, Li et al. (2018) declared that teachers can influence and improve language learners' motivation and engagement in classroom tasks through allowing more foreign language input in the classroom by encouraging student-student interactions. Moreover, there is limited research in terms of the relationship between FLE/Second Language Enjoyment (SLE) and different language skills. Since enjoyment is positively associated with language learners' proficiency, it is recommended to conduct further research to investigate the role of FLE in the development and improvement of language skills. It is noteworthy that since positive psychology constructs are dynamic and complicated, Dörnyei and Ryan (2015) proposed the necessity to move toward dynamic research approaches that contribute to the changing nature of language learning concepts in academic studies; for this purpose, future research on anxiety and enjoyment should consider longitudinal perspectives (Elahi Shirvan and Taherian, 2021).

\section{AUTHOR CONTRIBUTIONS}

The author confirms being the sole contributor of this work and has approved it for publication.

and PhD exam candidates of TEFL. J. English Lang. Teach. Learn. 13, 81-112.

Dewaele, J. M., and Alfawzan, M. (2018). Does the effect of enjoyment outweigh that of anxiety in foreign language performance? Stud. Sec. Lang. Learn. Teach. 8, 21-45. doi: 10.14746/ssllt.2018.8.1.2

Dewaele, J. M., and MacIntyre, P. D. (2014). The two faces of Janus? Anxiety and enjoyment in the foreign language classroom. Stud. Sec. Lang. Learn. Teach. 4, 237-274. doi: 10.14746/ssllt.2014.4.2.5

Dewaele, J. M., and MacIntyre, P. D. (2016). "Foreign language enjoyment and foreign language classroom anxiety. the right and left feet of FL learning?", in Positive Psychology in SLA, eds P. Macintyre, T. Gregersen, and S. Mercer (Bristol: Multilingual Matters), 215-236. doi: 10.21832/97817830953 60-010

Dewaele, J.-M. (2019). The effect of classroom emotions, attitudes toward English, and teacher behavior on willingness to communicate among English foreign language learners. J. Lang. Soc. Psychol. 38, 523-535. doi: 10.1177/ 0261927x19864996 
Dewaele, J.-M., and Dewaele, L. (2017). The dynamic interactions in foreign language classroom anxiety and foreign language enjoyment of pupils aged 12 to 18. A pseudo-longitudinal investigation. J. EuroSLA 1, 12-22. doi: 10.22599/ jesla.6

Dewaele, J.-M., and Dewaele, L. (2020). Learner-internal and learner-external predictors of Willingness to Communicate in the FL classroom. J. EuroSLA 2, 24-37. doi: 10.22599/jesla.37

Dewaele, J.-M., Witney, J., Saito, K., and Dewaele, L. (2018). Foreign language enjoyment and anxiety: the effect of teacher and learner variables. Lang. Teach. Res. 22, 676-697. doi: 10.1177/1362168817692161

Dörnyei, Z., and Ryan, S. (2015). The Psychology of the Language Learner Revisited. New York, NY: Routledge.

Elahi Shirvan, M. E., and Taherian, T. (2020). Affordances of the microsystem of the classroom for foreign language enjoyment. Hum. Arenas doi: 10.1007/s42087020-00150-6 Epub ahead of print.

Elahi Shirvan, M., and Taherian, T. (2021). Longitudinal examination of university students' foreign language enjoyment and foreign language classroom anxiety in the course of general English: latent growth curve modeling. Int. J. Biling. Edu. Biling. 24, 31-49. doi: 10.1080/13670050.2018.1441804

Elahi Shirvan, M., and Talebzadeh, N. (2018). Exploring the fluctuations of foreign language enjoyment in cvonversation: an idiodynamic perspective. J. Intercult. Commun. Res. 47, 21-37. doi: 10.1080/17475759.2017.1400458

Elahi Shirvan, M., Taherian, T., and Yazdanmehr, E. (2020). The dynamics of foreign language enjoyment: an ecological momentary assessment. Front. Psychol. 11:1391. doi: 10.3389/fpsyg.2020.01391

Elahi Shirvan, M., Taherian, T., and Yazdanmehr, E. (2021). Foreign language enjoyment: a longitudinal confirmatory factor analysis-curve of factors model. J.Multilingual Multicult. Dev. Epub ahead of print.

Fathi, J., and Derakhshan, A. (2019). Teacher self-efficacy and emotional regulation as predictors of teaching stress: an investigation of Iranian English language teachers. Teach. English Lang. 13, 117-143.

Fredrickson, B. L. (2001). The role of positive emotions in positive psychology: the broaden-and-build theory of positive emotions. Am. Psychol. 56, 218-226. doi: 10.1037/0003-066X.56.3.218

Fredrickson, B. L. (2004). "Gratitude, like other positive emotions, broadens and builds," in The Psychology of Gratitude, eds R. A. Emmons and M. E. McCullough (New York, NY: Oxford University Press), 145-166.

Gregersen, T. S., and MacIntyre, P. D. (eds) (2017). Innovative Practices In Language Teacher Education: Spanning The Spectrum From Intra-To InterPersonal Professional Development, Vol. 30. Switzerland, Cham: Springer.

Jin, Y., and Zhang, L. J. (2018). The dimensions of foreign language classroom enjoyment and their effect on foreign language achievement. Int. J. Biling. Educ. Biling. doi: 10.1080/13670050.2018.1526253 Epub ahead of print.

Khajavy, G. H., MacIntyre, P. D., and Barabadi, E. (2018). Role of the emotions and classroom environment in willingness to communicate. Stud. Sec. Lang. Acquis. 40, 605-624. doi: 10.1017/S0272263117000304

Lake, J. (2013). “Positive L2 self: linking positive psychology with L2 motivation," in Language Learning Motivation in Japan, eds M. T. Apple, D. Da Silva, and T. Fellner (Bristol: Multilingual Matters), 225-244. doi: 10.21832/9781783090518015

Li, C., Jiang, G., and Deweale, J. (2018). Understanding chinese high school students' foreign language enjoyment: validation of the chinese version of the foreign language enjoyment scale. System 76, 183-196. doi: 10.1016/j.system. 2018.06.004

MacIntyre, P. D. (2016). "So far so good: an overview of positive psychology and its contributions to SLA," in Second language learning and teaching.
Positive psychology perspectives on foreign language learning and teaching, eds D. Gabry's-Barker and D. Gałajda (Switzerland, Cham: Springer), 3-20. doi: 10.1007/978-3-319-32954-3_1

MacIntyre, P. D., and Gregersen, T. (2012). Emotions that facilitate language learning: the positive-broadening power of the imagination. Stud. Second Lang. Learn. Teach. 2, 193-213. doi: 10.14746/ssllt.2012.2.2.4

Macintyre, P. D., Gregersen, T., and Mercer, S. (2019). Setting an agenda for positive psychology in SLA: theory, practice, and research. Mod. Lang. J. 103, 262-274. doi: 10.1111/modl.12544

Mierzwa, E. (2018). The relationship between foreign language enjoyment and gender among secondary grammar school students. JECS 9, 117-135. doi: 10. 15503/jecs20182.117.135

Pekrun, R., Frenzel, A. C., Goetz, T., and Perry, R. P. (2007). "The control-value theory of achievement emotions: an integrative approach to emotions in education," in Emotion in education, eds P. A. Schutz and R. Pekrun (Amsterdam: Academic Press), 13-36. doi: 10.1016/b978-012372545-5/ 50003-4

Pishghadam, R., Derakhshan, A., Zhaleh, K., and Al-Obaydi, L. H. (2021). Students' willingness to attend EFL classes with respect to teachers' credibility, stroke, and success: a cross-cultural study of Iranian and Iraqi students' perceptions. Curr. Psychol. 40, 1-15. doi: 10.1007/s12144-02101738-Z

Resnik, P., and Dewaele, J.-M. (2020). Trait emotional intelligence, positive and negative emotions in first and foreign language classes: a mixedmethods approach. System 94:102324. doi: 10.1016/j.system.2020. 102324

Seligman, M. (2018). PERMA and the building blocks of well-being. J. Posit. Psychol. 13, 333-335. doi: 10.1080/17439760.2018.1437466

Seligman, M., and Csikszentmihalyi, M. (2000). Positive psychology: an introduction. Am. Psychol. 55, 5-14.

Snyder, C. R., and Lopez, S. J. (2009). Oxford Handbook Of Positive Psychology. Oxford: Oxford University Press.

Wei, H., Gao, K., and Wang, W. (2019). Understanding the relationship between grit and foreign language performance among middle school students: the roles of foreign language enjoyment and classroom environment. Front. Psychol. 10:1508. doi: 10.3389/fpsyg.2019.01508

Xie, F., and Derakhshan, A. (2021). A conceptual review of positive teacher interpersonal communication behaviors in the instructional context. Front. Psychol. 12:708490. doi: 10.3389/fpsyg.2021.708490

Conflict of Interest: The author declares that the research was conducted in the absence of any commercial or financial relationships that could be construed as a potential conflict of interest.

Publisher's Note: All claims expressed in this article are solely those of the authors and do not necessarily represent those of their affiliated organizations, or those of the publisher, the editors and the reviewers. Any product that may be evaluated in this article, or claim that may be made by its manufacturer, is not guaranteed or endorsed by the publisher.

Copyright (c) 2021 Zeng. This is an open-access article distributed under the terms of the Creative Commons Attribution License (CC BY). The use, distribution or reproduction in other forums is permitted, provided the original author(s) and the copyright owner(s) are credited and that the original publication in this journal is cited, in accordance with accepted academic practice. No use, distribution or reproduction is permitted which does not comply with these terms. 


\section{APPENDIX}

\section{The FLE scale}

To what extent do you agree with the following statements?

Strongly disagree/ Disagree/Undecided/Agree/Strongly agree

1. I can be creative

2. I can laugh off embarrassing mistakes in the FL

3. I don't get bored

4. I enjoy it

5. I feel as though I' $\mathrm{m}$ a different person during the FL class

6. I learnt to express myself better in the FL

7. I' $m$ a worthy member of the FL class

8. I've learnt interesting things

9. In class, I feel proud of my accomplishments

10. It's a positive environment

11. It's cool to know a FL

12. It's fun

13. Making errors is part of the learning process

14. The peers are nice

15. The teacher is encouraging

16. The teacher is friendly

17. The teacher is supportive

18. There is a good atmosphere

19. We form a tight group

20. We have common "legends", such as running jokes

21. We laugh a lot

\section{The FLCA scale}

1. Even if I am well prepared for FL class, I feel anxious about it

2. I always feel that the other students speak the FL better than I do

3. I can feel my heart pounding when I'm going to be called on in FL class

4. I don't worry about making mistakes in FL class (reverse-coded)

5. I feel confident when I speak in FL class (reverse-coded)

6. I get nervous and confused when I am speaking in my FL class

7. I start to panic when I have to speak without preparation in FL class

8. It embarrasses me to volunteer answers in my FL class 